\title{
Arıtılmış Atıksu Uygulamalarının Üç Farklı Mısır (Zea Mays L.) Çeşidinin Çimlenme ve Fide Gelişim Özelliklerine Etkisi
}

\author{
Yusuf Murat Kardeş ${ }^{1}$, Murat Karaer², Özge Doğanay Erbaş Köse ${ }^{3 *}$, Zeki Mut $^{4}$
}

Geliş / Received: 28/02/2020

Revize / Revised: 16/03/2020

Kabul / Accepted: 16/03/2020

\section{ÖZ}

Artan dünya nüfusu nedeniyle tatlı su bulunabilirliği sınırlı bir kaynak haline gelmektedir. Atık suyun tarımda yeniden kullanılması yetiştirilen ürünler için yararlı olan besinleri içerdiğinden dikkat çekmiştir. Atık su, bitkileri için besin kaynağı olarak kullanılabilmektedir. Ancak, hem çevre hemde bitki açısından toksitesi konusunda çok yönlü araştırmalara ihtiyaç bulunmaktadır. Bu çalışmada, farklı atık su konsantrasyonlarının (saf su, \% 25, \% 50, $\% 75$ ve \% 100) üç farklı mısır çeşidinin (Kefieros, Kerbanis, Kontigos) çimlenme ve fide gelişimi üzerine etkisi incelenmiştir. Çalışma, faktöriyel düzende tesadüf parselleri deneme desenine desenine göre 4 tekrarlı olarak yürütülmüştür. Deneme kontrollü şartlarda $25{ }^{\circ} \mathrm{C}$ yürütülmüştür. Çimlenme yüzdesi, fide uzunluğu, kök uzunluğu, fide yaş ve kuru ağırlığı, kök yaş ve kuru ağırlığı incelenmiştir. Çeşitler arasında incelenen tüm özellikler (çimlenme yüzdesi hariç) ve atık su konsantrasyonları arasında çeşitler bakımından istatistiki olarak önemli farklılıklar bulunmuştur. Çalışmada, \% 25 atık su konsantrasyonunun çimlenmeyi teşvik ettiği fakat artan konsantrasyonların azalttı ğı belirlenmiştir. Fide gelişimi üzerine $\% 75$ atık su konsantrasyonunun teşvik edici bir özelliğe sahip olduğu belirlenmiştir.

\footnotetext{
1İletişim: yusuf.murat.kardes@bilecik.edu.tr (https://orcid.org/0000-0001-7144-9612)

Bilecik Şeyh Edebali Üniversitesi Ziraat ve Doğa Bilimleri Fakültesi Tarla Bitkileri Bölümü, Bilecik

2İletişim: murat.karaer@bilecik.edu.tr (https://orcid.org/0000-0002-1920-181X)

Bilecik Şeyh Edebali Üniversitesi Ziraat ve Doğa Bilimleri Fakültesi Biyosistem Mühendisliği Bölümü, Bilecik

3*Sorumlu yazar iletișim: ozgedoganay.erbas@bilecik.edu.tr (https://orcid.org/0000-0003-0429-3325)

Bilecik Şeyh Edebali Üniversitesi Ziraat ve Doğa Bilimleri Fakültesi Tarla Bitkileri Bölümü, Bilecik

4İletişim: zeki.mut@bilecik.edu.tr (https://orcid.org/0000-0002-1465-3630)

Bilecik Şeyh Edebali Üniversitesi Ziraat ve Doğa Bilimleri Fakültesi Tarla Bitkileri Bölümü, Bilecik
} 


\title{
The Effect of Treated Wastewater Applications on Germination and Seedling Growth in Three Different Corn (Zea Mays L.) Cultivar
}

\begin{abstract}
Because of increasing world population, fresh water availability is becoming a finite resource. Re-use wastewater for agriculture has attracted attention as it includes nutrients, which are helpful for growing crops. Wastewater may be used as the nutrient source for the growing crops. But the toxicity of its can still be a reason for worry and research. In this study, the effects of different wastewater concentrations (pure water, $25 \%, 50 \%$, $75 \%$ and $100 \%$ ) germination and seedling growth of three corn cultivars (Kefieros, Kerbanis, Kontigos) were investigated. The study was carried out as with four replications according to randomized complete block design as a factorial. Trial was founded at $25{ }^{\circ} \mathrm{C}$ under controlled conditions. Seed germination, root length, shoot length, root fresh weight and dry weight, shoot fresh weight and dry weight were investigated. Among the cultivars in terms of all traits examined (except for seed germination) and among wastewater concentrations in terms of all properties were found as statistically significant differences. In the study, it was determined that $25 \%$ waste water concentration increased seed germination, but increased doses decreased seed germination. It was determined that wastewater up to $75 \%$ concentration has an encouraging feature on seedling development.
\end{abstract}

Keywords- Corn, waste Water, Germination, Seedling 


\begin{tabular}{|c|c|c|}
\hline & $\begin{array}{l}\text { BŞEÜ Fen Bilimleri Dergisi } \\
7(1), 113-120,2020\end{array}$ & $\begin{array}{l}\text { BSEU Journal of Science } \\
\text { DOI: } 10.35193 / \text { bseufbd.696021 }\end{array}$ \\
\hline & & 88-7575 (http://dergipark.gov.tr/bseufbd) \\
\hline
\end{tabular}

\section{GİRIŞ}

Artan dünya nüfusuyla birlikte suya olan ihtiyaç giderek artmakta ve dünyanın bazı bölgelerinde insan hayatına yönelik bir tehdit oluşturacak seviyelere ulaşabilmektedir. Dünyanın dört bir yanındaki bilim insanları, su tasarrufu için yeni yollar üzerinde çalışmaktadır. Özellikle sulama ve diğer amaçlar için, kentsel atık suyun tekrar kullanılması yoluyla suyun geri dönüşümü sağlanabilmektedir [1]. Atık suyun bertarafı özellikle büyük şehirlerde ve bertaraf için sınırlı alana sahip olan belediyelerde karşılaşılan büyük bir problemdir. Çevre sağlı̆ğı ve su kirliliğinin öneminin daha fazla anlaşılmasından dolayı atık suların güvenli ve faydalı bir şekilde yok edilmesi gerektiği konusunda farkındalıkta artmıştır. Atık su kullanımının sulamada çok sayıda faydaları olmasına rağmen bu suların yeniden kullanılmasının uygun olmayan şekillerde yapılması ciddi çevresel ve sağlık sorunları yaratabileceğinden [2], kısa ve uzun vadeli çevresel risklerin önüne geçebilmek için önlemler alınmalıdır. Atık su, sulama için uygun şekilde kullanıldığında, çevresel olarak uygun bir bertaraf uygulaması olarak kabul edilmektedir [3]. Çevrenin ve halk sağlığının korunması; atık su arıtımı, toprak ve bitki seçimi ile uygulama yöntemini içeren entegre yönetim uygulamaları ile sağlanabilir [4]. Bu entegre uygulamaları içeren bir atık su yönetimi ile atık suyun doğrudan yeraltı suyuna karışması önlenebilir ve ekosistemin kirlenmesini göreceli olarak azaltılabilir [4]. Atık suların çoğu, toprak verimliliğini ve mahsul üretimini artıran değerli besinler içermektedir [5, 6]. Bu suların arıtımı tüm dünyada, özellikle tropikal ve subtropikal ülkelerde yaygın olarak kullanılmaktadır $[7,8]$. Arıtılmış atık suların tarım da yeniden kullanımının sürdürülebilir tarımı teşvik etmek, su kaynaklarını korumak ve çevresel kirliliği önlemek gibi birçok faydası vardır.

Mısır (Zea mays L.), dünya da tahıllar içinde 197 milyon ha ekim alanı ile buğdaydan sonra ikinci sırada yer alırken, 1 milyar ton üretimi ile birinci sırada yer almaktadır [9]. Kültür bitkileri içerisinde dünyada en fazla üretimi yapılan mısır; insan gıdası, hayvan beslenmesi ve endüstride kullanılmaktadır. Gelişmiş ülkelerde üretilen mısırın büyük çoğunluğu hayvan yemi olarak kullanılırken, az gelişmiş ve gelişmekte olan ülkelerde ise insan gıdası olarak kullanılmaktadır. Son yıllarda hem artan üretim hem de "Biyoyakıt" gibi ürünlerin artan kullanımları ile birlikte mısırın önemi daha da artmışır [10]. Mısır bitkisi tarla bitkileri içerisinde suyu en ekonomik kullanan bitkidir. Ancak toplam transprasyon yüzeyi, oluşturduğu kuru madde miktarı ve yetiştiği dönemdeki yüksek sıcaklık nedeniyle, ihtiyaç duyduğu su miktarı fazladır. Ayrıca, mısır toraktan yüksek miktarda besin maddesi almaktadır. Su ve besin maddeleri uygun miktarda olduğunda yüksek tane verimi elde edilmektedir [11]. Arıtılmış atık suların içerdiği besin maddelerinden dolayı uygun seyreltme ve yönetim ile tarımda kullanılmaları gübre tasarrufu ve çevre kirliliğinde azaltma sağlayabilir. Bu çalışmada, 5 farklı konsantrasyonda arıtılmış atık suyun 3 farklı mısır çeşidinde, çimlenme ve fide gelişimi üzerine etkileri incelenmiştir.

\section{MATERYAL VE YÖNTEM}

\section{A. Arıtılmış Atık Su}

Çalışmada, Bilecik ilinin Söğüt ilçesinde bulunan arıtma tesisinden alınan evsel arıtılmış atık su kullanılmıştır. Arıtılmış atık suyun kimyasal analiz değerleri Tablo 1' de verilmiştir.

Tablo 1. Çalışmada kullanılan arıtılmış atık suyun kimyasal analiz sonuçları*

\begin{tabular}{lc}
\hline Arıtılmış Atık Su Parametreleri & Arıtılmıs Atık Su Değerleri \\
\hline TAKM (mg/lt) & 37.5 \\
KOİ (mg/lt) & 83.7 \\
BOİ (mg/lt) & 25.2 \\
pH (mg/lt) & 7.6 \\
Toplam Azot (mg/lt) & 10.0 \\
Toplam Fosfor (mg/lt) & 0.9 \\
\hline *Söğüt Belediyesi Atık Su Arıtma Tesisi, TAKM: Toplam Askıda Katı Madde, \\
KOİ: Kimyasal Oksijen İhtiyacı, BOİ: Biyolojik Oksijen Ihtiyacı
\end{tabular}


Arıtma tesisinden plastik kaplara alınan atık sular kullanılana kadar $+4{ }^{\circ} \mathrm{C}$ de saklanmıştır. Çalışmada kontrol (saf su) ile birlikte \% 25, \% 50, \% 75 ve \% 100 atık su konsantrasyonu olmak üzere 5 farklı doz kullanılmıştır.

\section{B. Çimlendirme Çalışmaları}

Bilecik Şeyh Edebali Üniversitesi Uygulama ve Araştırma alanında bulunan hızlı 1slah ve iklim odasında kurulan denemede Kerbanis, Kefieros ve Kontigos olmak üzere üç farklı mısır çeşidi kullanılmıştır. Bu çeşitlere kontrol olarak saf su ile 4 farklı konsantrasyonda (\% 25, \% 50, \% 75, \%100) arıtılmış atık su uygulanmıştır. Denemede, \% 25, \% 50 ve \% 75 arıtılmış atık su konsantrasyonları saf su le seyreltilerek elde edilmiştir. Deneme kontrollü şartlarda faktöriyel deneme desenine göre dört tekrarlı olarak kurulmuştur. Çimlendirme için plastik çimlendirme kapları kullanılmıştır. Denemede kullanılacak tohumlar \% 3'lük sodyumhipoklorit çözeltisinde $10 \mathrm{dk}$ bekletilip, musluk suyu ile birkaç defa yıkandıktan sonra saf suda durulanarak steril edilmiştir. Yüzey sterilizasyonu yapılan tohumlar kurutma kağıtları üzerine alınıp kurutulmuştur. Daha sonra içerisinde iki adet filtre kağıdı bulunan çimlendirme kaplarına 20'şer tohum konulmuştur. Tohumların üzerine farklı konsantrasyonları içeren arıtılmış atık sulardan $20 \mathrm{ml}$ eklenmiştir. Bu işlemlerden sonra çimlendirme kapları $25^{\circ} \mathrm{C}$ 'ye ayarlanmış bitki büyütme odasında karanlık ortamda 10 gün boyunca bekletilmiştir. Çim kını uzunluğu 2 mm'yi geçen tohumlar çimlenmiş olarak kabul edilmiş ve her gün sayımları yapılmıştır. Çimlenmenin 10. gününde her bir çimlendirme kabından 10 sürgün örnek olarak alınmış ve bu örneklerde kökçük ve fide uzunlukları ölçülmüştür [12]. Yine aynı örnekler kökçük ve fide kuru ağılıklarının belirlenmesi için ayrılmış ve $70{ }^{\circ} \mathrm{C}$ 'de sabit ağırlığa gelene kadar kurutulup tartılmıştır [13]. Elde edilen verilerin istatistiki analizleri MSTAT-C paket programı kullanılarak yapılmıştır. Farklılık gruplandırması Duncan testine göre yapılmıştır.

\section{BULGULAR VE TARTIŞMA}

Çalışmada 5 farklı arıtılmış atık su konsantrasyonunun üç mısır çeşidinin çimlenme ve fide gelişimi üzerine etkileri incelenmiştir. Çimlenme ve fide gelişimi üzerine çeşitlerin ve arıtılmış atık su konsantrasyonlarının etkilerini içeren ortalamalar Tablo 2' de verilmiştir. Denemede, çimlenme yüzdesi ve kök uzunluğu hariç incelenen özellikler bakımından çeşitler arasında, incelenen bütün özellikler bakımından ise konsantrasyonlar arasında istatistiki olarak önemli farklar belirlenmiştir. Çeşit $\times$ konsantrasyon interaksiyonu kök uzunluğu, sürgün yaş ağırlığı ve kök kuru ağırlığına istatistiki olarak önemli etki etmiştir.

En yüksek çimlenme yüzdesi \% 94.4 ile \% 25 arıtılmış atık su konsantrasyonundan elde edilmiş, \% 25 atık su konsantrasyonundan sonra arıtılmış atık su konsantrasyonları artıkça çimlenme yüzdesinin azaldığ gözlemlenmiştir. Çeşitlerin çimlenme yüzdeleri arasında istatistiki olarak fark görülmemiştir. Çeşit $\times$ konsantrasyon interaksiyonu incelendiğinde çimlenme yüzdesi \% 62.0 ile 95.9 arasında değişmiş olup, en yüksek çimlenme yüzdesi Kerbanis çeşidinin \% 25 atık su uygulamasından, en düşük ise Kefieros çeşidinin \% 100 atık su konsantrasyondan elde edilmiştir. Tekstil atık suyunun ve yüksek endüstriyel atık suyun tohum çimlenmesine etkisi üzerine yapılan çalışmalarda yüksek konsantrasyonların tohum çimlenmesini olumsuz etkilerken düşük konsantrasyonların teşvik ettiği tespit edilmiştir [14, 15].

Denemede sürgün uzunluğu 8.9 (Kerbanis) ile $14.6 \mathrm{~cm}$ (Kefieroz) arasında değişmiştir. En yüksek sürgün uzunluğu $12.8 \mathrm{~cm}$ ile \% 50 arıtılmış atık su konsantrasyonundan, en düşük sürgün uzunluğu ise $9.4 \mathrm{~cm}$ ile kontrol dozundan elde edilmiştir. Çeşit $\times$ konsantrasyon interaksiyonuna göre sürgün uzunlukları $7.3 \mathrm{~cm}$ ile 16.4 $\mathrm{cm}$ arasında değişmiş olup, en düşük sürgün uzunluğu kerbanis çeşidinin kontrol dozundan, en yüksek ise kefieros çeşidinin \% 50 ve \% 75 dozundan elde edilmiştir. Kök uzunluğu 13.5 (Kontigos) ile $14.4 \mathrm{~cm}$ (kerbanis) arasında değişmiştir. Kök uzunluğu en düşük $10.4 \mathrm{~cm}$ ile kontrol, en yüksek $15.7 \mathrm{~cm}$ ile $\% 75$ arıtılmış atık su dozundan elde edilmiştir. Çeşit $\times$ konsantrasyon interaksiyonuna göre en yüksek kök uzunluğu Kontigos çeşidinin \% 50 konsantrasyonundan $17.6 \mathrm{~cm}$ ile elde edilirken, en düşük kök uzunluğu ise $4.9 \mathrm{~cm}$ ile yine Kontigos çeşidinin Kontrol uygulamasından elde edilmiştir.

Sürgün yaş ve kuru ağırlığı en yüksek Kontigos çeşidinde elde edilirken, en düşük Kerbanis çeşidinde elde edilmiştir. Sürgün yaş ve kuru ağırlıkları \% 75 arıtılmış atık su konsantrasyonuna kadar artış göstermiş ve

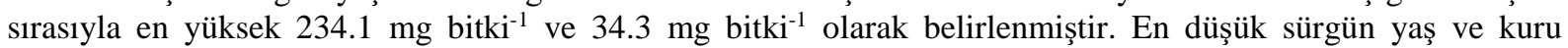


ağırlıkları ise \% 100 arıtılmış atık su konsantrasyonunda sırasıyla $148.6 \mathrm{mg} \mathrm{bitki}^{-1}$ ve $27.7 \mathrm{mg} \mathrm{bitki}^{-1}$ olarak belirlenmiştir. Çeşit $\times$ konsantrasyon interaksiyonuna göre sürgün yaş ağırlığı en yüksek $257.0 \mathrm{mg} \mathrm{bitki}^{-1}$ ile Kontigos çeşidinin \% 75 konsantrasyonundan, en düşük ise $117.3 \mathrm{mg} \mathrm{bitki}^{-1}$ ile Kontigos çeşidinin $\% 100$ konsantrasyonundan elde edilmiştir. Sürgün kuru ağırlıkları 21.3 ile $38.3 \mathrm{mg} \mathrm{bitki}^{-1}$ arasında değişmiştir. En düşük sürgün kuru ağırlığı Kontrol uygulamasında Kerbanis çeşidinden $\left(21.3 \mathrm{mg} \mathrm{bitki}{ }^{-1}\right)$, en yüksek ise \% 75 atık su konsantrasyonunda Kontigos çeşidinden $\left(40.7 \mathrm{mg}\right.$ bitki $\left.^{-1}\right)$ elde edilmiştir.

Tablo 2. Çalışmada kullanılan mısır çeşitlerinin ve dozlarının ortalama değerleri ${ }^{+}$

\begin{tabular}{|c|c|c|c|c|c|c|c|c|c|c|c|c|c|c|}
\hline \multirow[b]{2}{*}{ Çeșitler } & \multicolumn{2}{|c|}{$\mathbf{C ̧ Y}$} & \multicolumn{2}{|c|}{ SU } & \multicolumn{2}{|c|}{$\mathbf{K U}$} & \multicolumn{2}{|c|}{ SYA } & \multicolumn{2}{|c|}{ SKA } & \multicolumn{2}{|c|}{ KYA } & \multicolumn{2}{|c|}{ KKA } \\
\hline & & & & & & & & & & & & & & \\
\hline Kefieros & 75.2 & & 14.6 & $\mathrm{a}$ & 13.8 & & 197.7 & b & 32.7 & $\mathrm{a}$ & 117.5 & $\mathrm{c}$ & 31.0 & b \\
\hline Kerbanis & 82.5 & & 8.9 & $\mathrm{c}$ & 14.4 & & 169.1 & $\mathrm{c}$ & 25.9 & $\mathrm{~b}$ & 188.9 & $\mathrm{a}$ & 44.4 & $\mathrm{a}$ \\
\hline Kontigos & 78.4 & & 11.4 & $\mathrm{~b}$ & 13.5 & & 219.5 & $\mathrm{a}$ & 35.9 & $\mathrm{a}$ & 159.1 & $b$ & 42.4 & a \\
\hline \multicolumn{15}{|c|}{ Konsantrasyonlar } \\
\hline Kontrol & 91.7 & $\mathrm{~b}$ & 9.4 & $\mathrm{c}$ & 10.4 & d & 169.1 & $\mathrm{~b}$ & 28.4 & $\mathrm{c}$ & 135.3 & b & 36.2 & b \\
\hline$\% 25$ & 94.4 & $\mathrm{a}$ & 12.1 & $b$ & 14.5 & $b$ & 209.9 & $\mathrm{a}$ & 33.1 & b & 165.6 & a & 39.8 & $\mathrm{a}$ \\
\hline$\% 50$ & 73.9 & $\mathrm{c}$ & 12.5 & $a b$ & 15.5 & $a b$ & 215.6 & $\mathrm{a}$ & 33.9 & b & 176.2 & $\mathrm{a}$ & 42.6 & $\mathrm{a}$ \\
\hline$\% 75$ & 68.3 & $\mathrm{~cd}$ & 12.8 & $\mathrm{a}$ & 15.7 & $\mathrm{a}$ & 234.1 & $\mathrm{a}$ & 34.3 & $\mathrm{a}$ & 167.3 & $\mathrm{a}$ & 41.3 & $\mathrm{a}$ \\
\hline$\% 100$ & 65.0 & $\mathrm{~d}$ & 11.5 & c & 13.4 & $\mathrm{c}$ & 148.6 & b & 27.7 & $\mathrm{~d}$ & 131.3 & $\mathrm{~b}$ & 36.4 & $\mathrm{~b}$ \\
\hline
\end{tabular}

ÇY: Çimlenme Yüzdesi (\%), SU: Sürgün Uzunluğu $(\mathrm{cm})$, KU: Kök uzunluğu $(\mathrm{cm})$, SYA: Sürgün Yaş Ağırlığı (mg bitki $\left.{ }^{-1}\right)$, SKA: Sürgün Kuru Ağırlığı (mg bitki $\left.{ }^{-1}\right)$, KYA: Kök Yaș Ağırlığı (mg bitki ${ }^{-1}$ ), KKA: Kök Kuru Ağırlığı (mg bitki $\left.{ }^{-1}\right)$, + Her sütunda aynı harflerle gösterilen ortalamalar arasındaki \% 1 önem düzeyinde fark yoktur.

Kök yaş ağırlı̆̆ı 117.5 (Kefieros) ile $189.7 \mathrm{mg} \mathrm{bitki}^{-1}$ (Kerbanis), kök kuru ağırlığı 31.0 (Kefieros) ile $44.4 \mathrm{mg} \mathrm{bitki}{ }^{-1}$ (Kerbanis) arasında değişmiştir. Kök yaş ve kuru ağırlıkları \% 50 arıtılmış atık su konsantrasyonuna kadar artmış daha sonra azalmıştır. En yüksek kök yaş ve kuru ağırlığı sırasıyla $176.2 \mathrm{mg}$ bitki $^{-1}$ ve $42.6 \mathrm{mg} \mathrm{bitki}^{-1}$ ile \% 50 atık su konsantrasyonunda belirlenmiştir. En düşük kök yaş ağırlığı $131.3 \mathrm{mg}$ bitki $^{-1}$ ile \% 100 atık su konsantrasyonundan, en düşük kök kuru ağırlığı ise $36.2 \mathrm{mg} \mathrm{bitki}^{-1}$ ile kontrol uygulamasından elde edilmiştir. Çeşit $\times$ konsantrasyon interaksiyonuna göre kök yaş ağırlıkları en düşük 100.3 mg bitki ${ }^{-1}$ ile Kefieros çeşidinde \% 100 konsantrasyonda, en yüksek $217.0 \mathrm{mg} \mathrm{bitki}^{-1}$ ile Kerbanis çeşidinde \% 50

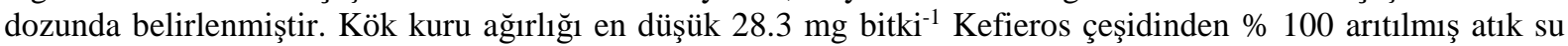
konsantrasyonunda, en yüksek ise $48.7 \mathrm{mg} \mathrm{bitki}^{-1}$ ile Kerbanis çeşidinin \% 50 atık su konsantrasyonunda elde edilmiştir (Tablo 3).

Tablo 3. Mısır çeşitlerinde atık su uygulamalarının ortalama çimlenme ve fide büyüme özellikleri

\begin{tabular}{|c|c|c|c|c|c|c|c|c|c|c|}
\hline Çeşitler & Konsantrasyonlar & ÇY & SU & $\mathbf{K}$ & & SY & & SKA & KYA & KKA \\
\hline \multirow{5}{*}{ Kefieros } & Kontrol & $\overline{90.8}$ & 12.2 & 13.6 & $\mathrm{~cd}$ & 154.7 & $\mathrm{~d}$ & 30.0 & 111.0 & 30.7 ef \\
\hline & $25 \%$ & 92.6 & 15.6 & 14.3 & bcd & 218.3 & bc & 34.3 & 132.3 & 33.7 \\
\hline & $50 \%$ & 67.4 & 16.4 & 14.6 & bcd & 219.3 & $\mathrm{bc}$ & 33.7 & 122.7 & 31.7 \\
\hline & $75 \%$ & 63.1 & 16.4 & 16.1 & $a b$ & 231.7 & $a b c$ & 36.3 & 121.0 & 30.7 \\
\hline & $100 \%$ & 62.0 & 12.5 & 10.5 & $\mathrm{e}$ & 164.7 & $\mathrm{~d}$ & 29.3 & 100.3 & $28.3 \mathrm{f}$ \\
\hline \multirow{5}{*}{ Kerbanis } & Kontrol & 91.9 & 7.3 & 12.8 & $\mathrm{~d}$ & 121.7 & $\mathrm{e}$ & 21.3 & 146.7 & 42.7 \\
\hline & $25 \%$ & 95.9 & 8.6 & 14.8 & bcd & 164.7 & $\mathrm{~d}$ & 27.0 & 186.7 & $43.3 \mathrm{abc}$ \\
\hline & $50 \%$ & 78.5 & 9.3 & 14.9 & bcd & 181.7 & $\mathrm{~d}$ & 27.3 & 217.0 & $48.7 \mathrm{a}$ \\
\hline & $75 \%$ & 76.9 & 10.8 & 15.6 & $a b c$ & 213.7 & $\mathrm{c}$ & 28.3 & 208.7 & 45.0 \\
\hline & $100 \%$ & 69.3 & 8.5 & 14.1 & bcd & 163.7 & $\mathrm{~d}$ & 25.3 & 185.3 & 42.3 \\
\hline \multirow{5}{*}{ Kontigos } & Kontrol & 92.4 & 8.6 & 4.9 & $\mathrm{f}$ & 231.0 & $a b c$ & 34.0 & 148.3 & 35.3 \\
\hline & $25 \%$ & 94.8 & 11.9 & 14.4 & bcd & 246.7 & $a b$ & 38.0 & 177.7 & 42.3 \\
\hline & $\mathbf{5 0 \%}$ & 75.7 & 12.6 & 17.6 & $\mathrm{a}$ & 245.7 & $a b$ & 40.7 & 189.0 & $47.3 \mathrm{a}$ \\
\hline & $75 \%$ & 65.0 & 10.3 & 15.7 & $a b c$ & 257.0 & $\mathrm{a}$ & 38.3 & 172.3 & 48.3 \\
\hline & $100 \%$ & 63.9 & 13.4 & 14.7 & bcd & 117.3 & $\mathrm{e}$ & 28.3 & 108.3 & $38.7 \mathrm{bcc}$ \\
\hline
\end{tabular}

+ Her sütunda aynı harflerle gösterilen ortalamalar arasındaki \% 1 önem düzeyinde fark yoktur. 
Kurak ve yarı kurak bölgelerde, kaliteli su kaynakları gittikçe azalmakta ve kentsel su temini için öncelikli olarak görülmektedir. Bu nedenle tarım alanlarının arıtılmış atık su ile sulanması son yıllarda üzerinde durulan önemli konulardan biri olmuştur [16, 17]. Ekonomik ve etkin olarak kullanılabilecek su kaynaklarından biri kentsel arıtılmış atık sulardır [18]. Sulama suyu içme suyuyla kıyaslandığında biraz daha düşük bir kalite sınıfında olmasında bir sakınca yoktur. Atık suyun tarım için yeniden kullanılmasının atık su miktarını azaltmak, gübre olarak besin geri kazanımı ve mahsul üretimini artırmak gibi çeşitli avantajları vardır. Arıtılmış atık suyun sulama için tekrar kullanılması, özellikle kurak ve yarı kurak bölgelerde su kıtlığının önlenebilmesi için dikkate alınması gereken bir konudur [19]. Atık su, bitki büyümesini iyileştirebilecek yüksek besin elementi değerine sahiptir [20].

Yapılan çalışmalarda nohut, mercimek ve bezelye'de kök ve sürgün uzunluğunun, buğday ve çeltikte sürgün uzunluğunun, domateste kök uzunluğunun, misırda sürgün ve kök uzunluğunun belirli atık su konsantrasyona kadar arttığını, daha yüksek konsantrasyonlarda azaldığını bildirmişlerdir[14, 21, 22, 23]. Bu düşüşün yüksek konsantrasyonda atık suyun toksisitesinin olumsuz etkisinin daha fazla olmasından kaynaklanabileceği bildirilmiştir [24, 25].

Barbunya tohumlarının çimlenmesi üzerine yapılan bir çalışmada, atık suyun $\% 50$ konsantrasyona kadar çimlenme üzerine bir etki göstermediği, fakat \% 75 ve \% 100 atık su konsantrasyonlarında çimlenmenin olumsuz etkilendiği görülmüştür [26]. Yem bitkileri üzerine yapılan araştırmalarda, atık su ile iki yıl boyunca sulama sonucu arpa biyokütlesinin arttığı gözlemlenmiştir [27]. Tüm büyüme aşamalarında atık su ile sulama işleminin en iyi biyolojik mısır veriminin elde edilmesine neden olduğunu bildirmiştir [28]. Fasulye çeşitlerinde çimlenme ve fỉde gelişimi üzerine yapılan çalışmada, arıtılmış atık suyun \% 75 konsantrasyona kadar teşvik edici bir etkisi olduğu sonucuna varılmıştır [29].

\section{SONUÇ}

Bu çalışmada, arıtılmış evsel atık suyun mısır çeşitlerinde çimlenme yüzdesi üzerine $\% 25$ arıtılmış atık su konsantrasyonuna, fide gelişimi üzerine \% 75 arıtılmış atık su konsantrasyonuna kadar teşvik edici bir etki gösterdiği sonucuna varılmıştır. Bunun atık su içinde mevcut olan besin elementlerinin varlığı olabileceği düşünülmektedir. Sulamada arıtılmış atık su kullanımı ürünün büyümesini arttırırken, kimyasal gübre maliyetinde tasarruf ve yeraltı suyuna yönelik kirlilik risklerinde azalma sağlayacağı düşünülmektedir. Fakat arıtılmış atık suların sulama amacıyla kullanılmadan önce seyreltilmesi önerilmektedir.

\section{KAYNAKLAR}

[1] Srivastava, R.K. (1991). Effect of paper mill effluent on seed germination and early growth performance of radish and onion. J. Ecotoxicol. Environ. Monit., 1: 13-18.

[2] Angelakis, A. N., Do Monte, M. M., Bontoux, L., \& Asano, T. (1999). The status of wastewater reuse practice in the Mediterranean basin: need for guidelines. Water research, 33 (10), 2201-2217.

[3] Papadopoulos, I. (1995). Wastewater Management for Agriculture Protection in the Near East Region; FAO, Regional Office for the Near East: Cairo, Egypt, Tech. Bull. pp. 56-58.

[4] Gori, R., Ferrini, F., Nicese, F.P., \& Lubello C (2000). Effect of reclaimed wastewater on the growth and nutrient content of three landscape shrubs. J. Environ. Hortic., 18(2), 108-114.

[5] Mohammad, M. J., \& Athamneh, B. M. (2004). Changes in soil fertility and plant uptake of nutrients and heavy metals in response to sewage sludge application to calcareous soils. Journal of Agronomy, 3(3), 229236.

[6] Ahmad, A., Inam, A., Ahmad, I., Hyat, S., \& Azam, Z.M. (2003). Response of sugarcane to treated wastewater of oil refinery. J. Environ. Biol. 24(2), 141-146.

[7] Khan, M. A., Shaukat, S. S., \& Khan, M. A. (2008). Economic benefits from irrigation of maize with treated effluent of waste stabilization ponds. Pak. J. Bot, 40(3), 1091-1098. 
[8] Khan, M. A., Shaukat, S. S., Hany, O., \& Jabeen, S. (2010). Irrigation of sorghum crop with waste stabilization pond effluent: growth and yield responses. Pak. J. Bot, 42(3), 1665-1674.

[9] Food Agriculture Organization. (2019). Statistical Databases, http://faostat.fao.org, (erişim tarihi: 20.02.2020).

[10] Taşdan K. (2016). T.C. Gıda Tarım ve Hayvancılık Bakanlığı, Tarımsal Ekonomi ve Politika Geliştirme Enstitüsü, Misır Durum / Tahmin (2016 / 2017) Yayın No: 280, ISBN: 978- 605-9175-67-8.

[11] Kaplan, M., Karaman, K., Kardes, Y. M., \& Kale, H. (2019). Phytic acid content and starch properties of maize (Zea mays L.): Effects of irrigation process and nitrogen fertilizer. Food chemistry, 283, 375-380.

[12] Daud, M.K., Hassan, S., Azizullah, A., Jamil, M., Rehan, N., Irum, R., Qaiser, MK., \& Zhu, SJ (2016). Physiological, biochemical, and genotoxic effects of wastewater on maize seedlings. Polish Journal of Environmental Studies, 25(2), 563-571.

[13] Atak, M., Kaya, M. D., Kaya, G., Çikili, Y., \& Çiftçi, C. Y. (2006). Effects of NaCl on the germination, seedling growth and water uptake of triticale. Turkish Journal of Agriculture and Forestry, 30(1), 39-47.

[14] Khan, M. G., Daniel, G., Konjit, M., Thomas, A., Eyasu, S. S., \& Awoke, G. (2011). Impact of textile waste water on seed germination and some physiological parameters in pea (Pisum sativum L.), Lentil (Lens esculentum L.) and gram (Cicer arietinum L.). Asian Journal of Plant Sciences, 10(4), 269.

[15] Nagda, G. K., Diwan, A. M., \& Ghole, V. S. (2006). Seed germination bioassays to assess toxicity of molasses fermentation based bulk drug industry effluent. Electronic Journal of Environmental, Agricultural and Food Chemistry, 5(6), 1598-1603.

[16] Food Agriculture Organization. (2013). Statistical Databases, http://faostat.fao.org, (erişim tarihi: 20.01.2020).

[17] Jalali, M., Merikhpour, H., Kaledhonkar, M. J., \& Van Der Zee, S. E. A. T. M. (2008). Effects of wastewater irrigation on soil sodicity and nutrient leaching in calcareous soils. Agricultural water management, 95(2), 143-153.

[18] Feizi, M., \& Rastghalam, Z. (2012). The effect of treated wastewater irrigation on accumulation of heavy metals in selected plants. In The 1 st International and The 4 th National Congress on Recycling of Organic Waste in Agriculture, April (pp. 26-27).

[19] Al-Jasser, A. O. (2011). Saudi wastewater reuse standards for agricultural irrigation: Riyadh treatment plants effluent compliance. Journal of King Saud University-Engineering Sciences, 23(1), 1-8.

[20] Kiziloglu, F., Turan, M., Sahin, U., Angin, I., Anapali, O., \& Okuroglu, M. (2007). Effects of wastewater irrigation on soil and cabbage $\square$ plant (brassica olerecea var. capitate cv. yalova $\square$ ) chemical properties. Journal of Plant Nutrition and Soil Science, 170(1), 166-172.

[21] Dash, A.K. (2012). Impact of domestic waste water on seed germination and physiological parameters of rice and wheat. Int. J. Res. Rev. Appl. Sci.12: 280-286

[22] Daifi, H., Alemad, A., Khadmaoui, A., El hadi, M., El kharrim, K., \& Belghyti, D. (2015). Effect of purified industrial wastewater on the growth of tomato plant (Lycopersicon esculentum). Int. J. Pure App. Biosci. 3 (4), 57-64

[23] Daud, M.K., Hassan, S., Azizullah, A., Jamil, M., Rehan, N., Irum, R., Qaiser, MK., \& Zhu, S.J. (2016). Physiological, biochemical, and genotoxic effects of wastewater on maize seedlings. Polish Journal of Environmental Studies, 25(2), 563-571. 
[24] Ramana, S., Biswas, AK., Kundu, S., Saha, J.K., Yadav, R.B.R. (2002). Effect of distillery effluent on seed germination in some vegetable crops. Biores. Technol., 82, 273-275.

[25] Yousaf, I., Ali, S.M., \& Yasmin, A. (2010). Germination and early growth response of Glycine max varieties in textile and paper industry effluents. Pak. J. Bot. 42: 3857-3863.

[26] Mohammad A, Khan AU (1985). Effect of textile factory effluent on soil and crop plants. Environ. Pollun. (Series A) 37, 131-148.

[27] Munir, J., Rusan, M., Hinnawi, S., \& Rusan, L. (2007). Long term effect of wastewater irrigation of forage crops on soil and plant quality parameters. Desalination, 215, 143-152.

[28] Alizadeh, A., Bazari, M.E., Velayati, S., Hasheminia, M., \& Yaghmaie, A. (2001). Irrigation of corn with wastewater. In: Ragab G, Pearrce J, chakgkim S, Nairizi A. Hamdy (Eds.), ICID International Workshop on Wastewater Reuse and Management. Seoul, Korea, pp. 147-154.

[29] Kardeş, Y. M., Mut, Z., Gültaş, H. T., Erbaş Köse, Ö. D., \& Karaer, M. (2019). Effect of Treated Wastewater on Germination and Seedling Growth of Two Different Bean (Phaseolus vulgaris L.) Cultivar. III. International Eurasian Agriculture and Natural Sciences Congress, 17-20 October, s. 505-511, Antalya. 